\title{
Mortality and causes of death in the WHO multinational study of vascular disease in diabetes
}

\author{
N.J. Morrish ${ }^{1}$, S.-L.Wang ${ }^{2}$, L.K.Stevens ${ }^{2}$, J.H.Fuller ${ }^{2}$, H. Keen ${ }^{3}$ and the WHO Multinational Study Group* \\ ${ }^{1}$ North Bedfordshire Diabetes Centre, Bedford Hospital, Bedford, UK \\ ${ }^{2}$ EURODIAB, Department of Epidemiology \& Public Health, University College London, UK \\ ${ }^{3}$ Unit for Metabolic Medicine, Guy's Hospital, London, UK
}

\section{Abstract}

Aims/hypothesis. We aimed to examine the mortality rates, excess mortality and causes of death in diabetic patients from ten centres throughout the world.

Methods. A mortality follow-up of 4713 WHO Multinational Study of Vascular Disease in Diabetes (WHO MSVDD) participants from ten centres was carried out, causes of death were ascertained and age-adjusted mortality rates were calculated by centre, sex and type of diabetes. Excess mortality, compared with the background population, was assessed in terms of standardised mortality ratios (SMRs) for each of the 10 cohorts.

Results. Cardiovascular disease was the most common underlying cause of death, accounting for $44 \%$ of deaths in Type I (insulin-dependent) diabetes mellitus and $52 \%$ of deaths in Type II (non-insulin-dependent) diabetes mellitus. Renal disease accounted for $21 \%$ of deaths in Type I diabetes and $11 \%$ in Type II diabetes. For Type I diabetes, all-cause mortality rates were highest in Berlin men and Warsaw women, and lowest in London men and Zagreb women. For Type II diabetes, rates were highest in Warsaw men and Oklahoma women and lowest in Tokyo men and women. Age adjusted mortality rates and SMRs were generally higher in patients with Type I diabetes compared with those with Type II diabetes. Men and women in the Tokyo cohort had a very low excess mortality when compared with the background population.

Conclusion/interpretation. This study confirms the importance of cardiovascular disease as the major cause of death in people with both types of diabetes. The low excess mortality in the Japanese cohort could have implications for the possible reduction of the burden of mortality associated with diabetes in other parts of the world. [Diabetologia (2001) 44 [Suppl 2]: S14-S21]

Keywords Mortality, Type I (insulin-dependent) diabetes mellitus, Type II (non-insulin-dependent) diabetes mellitus, standardised mortality ratio, cardiovascular disease, renal disease.
Attempts to gain information about deaths in diabetes have always been confused by the difficulty in authenticating both the diagnosis of diabetes and the

Corresponding author: Dr. J.H. Fuller, Department of Epidemiology \& Public Health, University College London, 1-19 Torrington Place, London WC1E 6BT, UK

Abbreviations: WHO MSVDD, World Health Organization Multinational Study of Vascular Disease in Diabetes; SMRs, standardised mortality ratios; DERI, Diabetes Epidemiology Research International Study; ICD, International classification of diseases.

* See Reference 26 for list of investigators cause of death. This applies especially if death certificates are the only source of information as diabetes is often omitted from the certificate [1].

The Annual World Health Statistics of 1978 to 1985 [2] showed that deaths attributed directly to diabetes varied from 10 to 30 for every 1000 deaths of all causes in industrialised countries and from 4 to 40 in other countries. These variations in reported diabetes mortality could arise from true differences in case fatality rates as well as from diverse national practices in the certification of deaths.

There is little specific information about mortality in Type I (insulin-dependent) diabetes mellitus and 
A Type I diabetes

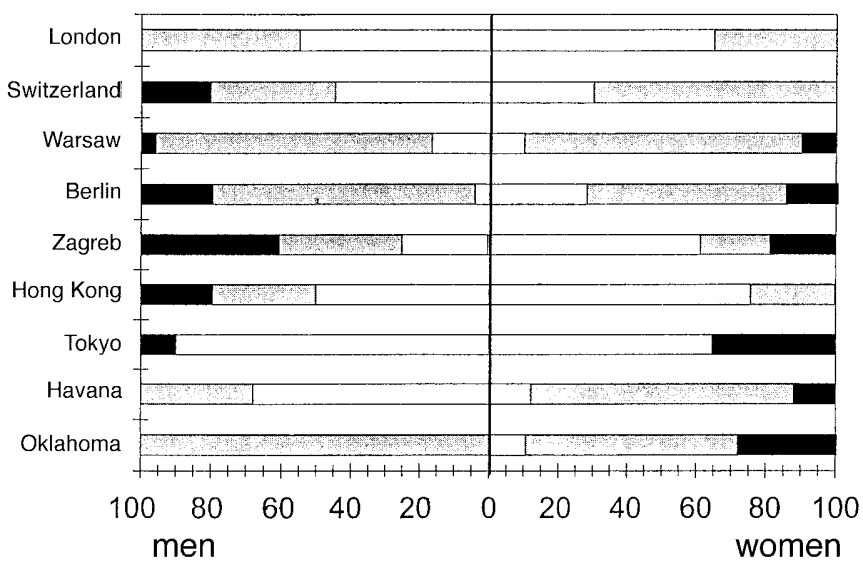

B Type II diabetes

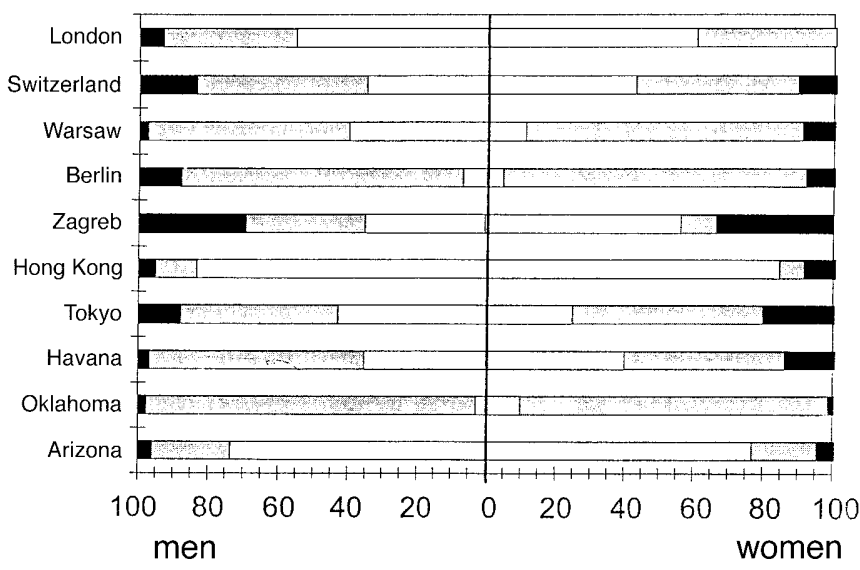

Fig. 1A, B. Distribution (\%) of confidence scores $(1 \square ; 2 \square$; 3 ) for death certificate and other medical information by centre, diabetes type and sex (see text for definition of scores)

such studies that exist are usually clinic based [3]. Mortality in Type II (non-insulin-dependent) diabetes mellitus is approximately twice that of the background populations [4, 5]. Published information highlights the importance of cardiovascular disease as a cause of mortality in Type I [6] and in Type II diabetes [7-9].

The World Health Organisation Multinational Study of Vascular Disease in Diabetes (WHO MSVDD) provided an opportunity to follow defined and comparable groups of patients with known diabetes and to look at the causes of mortality in the whole cohort and in each of the study centres from various geographical locations. The follow-up used a common methodology to examine the cause of death in all the participating study centres and is thus able to provide both an overview of mortality in a large group of patients with diabetes and to make comparisons of diabetes mortality in different geographically located centres.

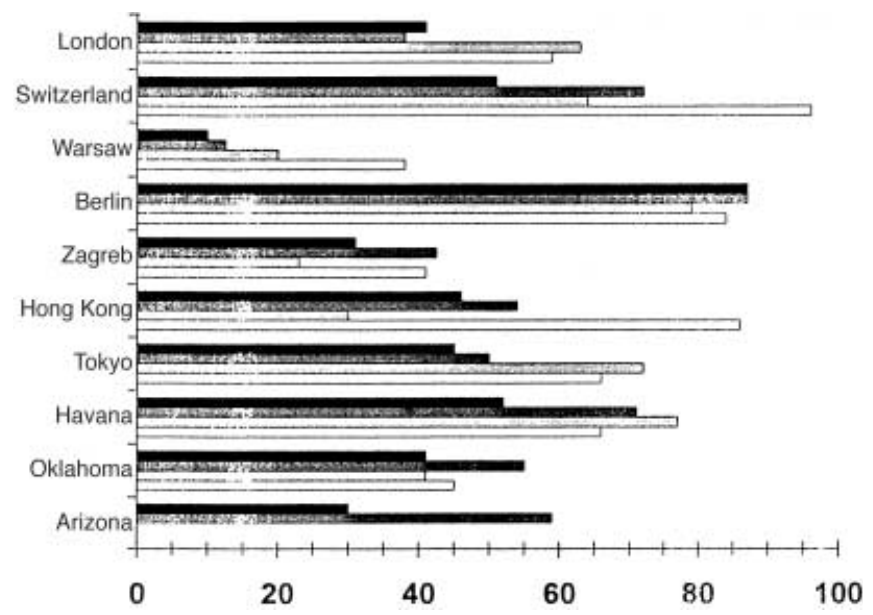

Fig. 2. Percentage of death certificates with diabetes mentioned by centre, diabetes type and sex. $\mathbf{\square}$, Men Type II diabetes; $\square$, Women Type II diabetes; $\square$, Men Type I diabetes; $\square$, Women Type I diabetes

\section{Subjects and methods}

A general description of the WHO study methodology has been published elsewhere [10]. This mortality follow-up is based on deaths in the original cohorts reported up to January $1^{\text {st }} 1988$. The number of deaths is therefore greater than that reported in the WHO MSVDD general description and morbidity paper [26] which only included deaths up to January $1^{\text {st }}, 1983$. The centres were asked to verify the life or death status for the patients in their groups on this date and to provide as much information as possible for the patients who had died. Information on the deceased patients could be in the form of death certificates, autopsy results or clinical records. Satisfactory information on deaths before this date is available from ten centres: London, Switzerland, Warsaw, Berlin, Zagreb, Hong Kong, Tokyo, Havana, Arizona and Oklahoma. A total of 30 subjects were untraceable $(<5 \%$ of the sample). Thus life or death status was ascertained for 4713 patients.

An independent committee of physicians assessed the information available for each patient reported dead and the cause of death was coded using the $9^{\text {th }}$ revision of the International Classification of Diseases (ICD) [24]. A code was assigned for more than $95 \%$ of the deaths, the remaining cases having insufficient information to make coding possible.

The amount and quality of the information available from the ten centres varied widely. The data was classified by centre by assigning to each decedent a 'confidence score' derived as follows:

(1) Death certificate available together with supporting data such as a summary of terminal illness or autopsy report.

(2) Only death certificate available.

(3) Death certificate not available but other clinical information given.

These scores are shown by sex and diabetes type (Fig.1). London, Hong Kong and Tokyo had a high percentage of deaths with a confidence score of 1 for both men and women with Type I diabetes. High scores were seen for patients with Type II diabetes among the Hong Kong and Arizona cohorts.

The percentage of death certificates mentioning diabetes varied widely (Fig. 2); for patients with Type I diabetes it rang- 
Table 1. Mean Follow up in years for each centre by diabetes type and sex

\begin{tabular}{|c|c|c|c|c|c|c|c|c|}
\hline \multirow[b]{3}{*}{ Centre } & \multicolumn{4}{|c|}{ Type I (insulin-dependent) diabetes mellitus } & \multicolumn{4}{|c|}{ Type II (non-insulin-dependent) diabetes mellitus } \\
\hline & \multicolumn{2}{|l|}{$\overline{\text { men }}$} & \multicolumn{2}{|c|}{ women } & \multicolumn{2}{|l|}{$\overline{\text { men }}$} & \multicolumn{2}{|c|}{ women } \\
\hline & mean & $\mathrm{SD}$ & mean & SD & mean & $\mathrm{SD}$ & mean & SD \\
\hline Switzerland & 10.6 & 3.3 & 11.4 & 2.6 & 10.8 & 3.3 & 11.4 & 2.9 \\
\hline Warsaw & 9.3 & 3.5 & 10.0 & 3.2 & 9.3 & 3.6 & 10.6 & 2.3 \\
\hline Berlin & 8.3 & 4.1 & 10.4 & 2.7 & 10.3 & 3.2 & 10.6 & 3.0 \\
\hline Tokyo & 9.0 & 4.0 & 11.0 & 1.9 & 10.9 & 1.9 & 11.0 & 1.8 \\
\hline Havana & 8.4 & 3.7 & 9.4 & 3.0 & 9.4 & 3.1 & 10.0 & 2.6 \\
\hline Oklahoma & 9.2 & 3.6 & 9.7 & 3.3 & 10.2 & 3.4 & 10.4 & 3.2 \\
\hline Arizona & - & - & - & - & 8.4 & 2.6 & 9.1 & 1.8 \\
\hline Total & 8.8 & 3.5 & 9.6 & 3.0 & 9.4 & 3.3 & 9.8 & 2.9 \\
\hline
\end{tabular}

ed from $20 \%$ among men from Warsaw to $96 \%$ among women from Switzerland. The proportion of certificates mentioning diabetes was generally lower in patients with Type II diabetes than in those with Type I diabetes, with a range from $10 \%$ for men in Warsaw to $87 \%$ for either sex in Berlin.

The methods of calculating age-adjusted all-cause mortality rates and Standardised Mortality Ratios (SMRs) for each centre have been described in detail [25]. The source of mortality data in the background population for comparison with diabetic patients depended on where and when the diabetic patients were recruited. For the centres in Switzerland, Hong Kong, Poland, former German Democratic Republic (GDR), former Yugoslavia and Cuba the national death rates were used as the reference. For the other four centres, namely London, Tokyo and the non-diabetic Pima Indians of Arizona and Oklahoma, regional death rates were used. Mortality in each cohort of diabetic patients was compared with mortality in the general population by means of an age-adjusted SMR using the person-years computer software. The SMR was the ratio of the number of deaths observed in the diabetic patients to the expected number of deaths in the background population, multiplied by 100 . An SMR greater than 100 indicates excess mortality in a given cohort compared with the standard population.

\section{Results}

Of the 4713 diabetic patients who were successfully followed, 1099 (23\%) are known to have died during the study period, 365 with Type I diabetes and 734 with Type II diabetes. The mean duration of followup in years for the mortality part of the study are shown in Table 1 . The Hong Kong cohort was only followed until the $1^{\text {st }}$ of January 1983 and had a shorter duration (about 6 years) of follow-up than the other centres (10 years). The follow-up status of subjects in each participating centre by sex and diabetes type are indicated in Table 2. Ascertainment was complete in $97 \%$ of patients with Type I diabetes and $96 \%$ of those with Type II diabetes overall. Patients who did not have a 'last known alive' date have been excluded from the analysis. The mean ages at death of the patients who died were very sim- ilar for all the centres both by type of diabetes and by sex (Table 3 ).

Causes of death. The underlying causes of death determined by the WHO Study Mortality Committee are given in Table 4. Cardiovascular diseases (ICD codes 390-459, 798.1) were the most common cause of death accounting for $44 \%$ of the 355 deaths from natural causes among patients with Type I diabetes and $52 \%$ of the 709 deaths in patients with Type II diabetes. Malignant neoplasms (ICD codes 140-209) were assigned as the underlying cause of death in 39 (11\%) patients with Type I diabetes and 99 (14\%) patients with Type II diabetes. Diabetes (ICD code 250, except 250.3) was assigned as the underlying cause in only 35 deceased subjects, 16 of them with Type I diabetes and 19 with Type II diabetes. Renal disease including diabetic nephropathy (ICD codes $580-589,250.3$ ) accounted for $21 \%$ of all deaths of patients with Type I diabetes and $11 \%$ of those with Type II diabetes.

The proportions of deaths assigned to ischaemic heart disease (ICD code 410-414), cerebrovascular disease (ICD codes 430-438), sudden death (ICD code 798.1) and other cardiovascular causes among the centres are shown in Figure 3. Ischaemic heart disease had the greatest proportion of cardiovascular deaths in all centres except for women with Type I diabetes in Zagreb, men with Type I diabetes in Hong Kong and patients with Type II diabetes in Tokyo and Hong Kong where cerebrovascular deaths were more common.

Age-adjusted mortality rates. Age-adjusted all-cause mortality rates per 1000 person years from 1975 to 1987 for each centre are given in Table 5. This shows a wide variation in rates between the ten centres. The mortality amongst men with Type I diabetes was four times higher in Berlin than in London, which had the lowest rate. There was less variation among the women with Type I diabetes with War- 
Table 2. Life or death status distribution at follow-up for each centre by diabetes type and sex

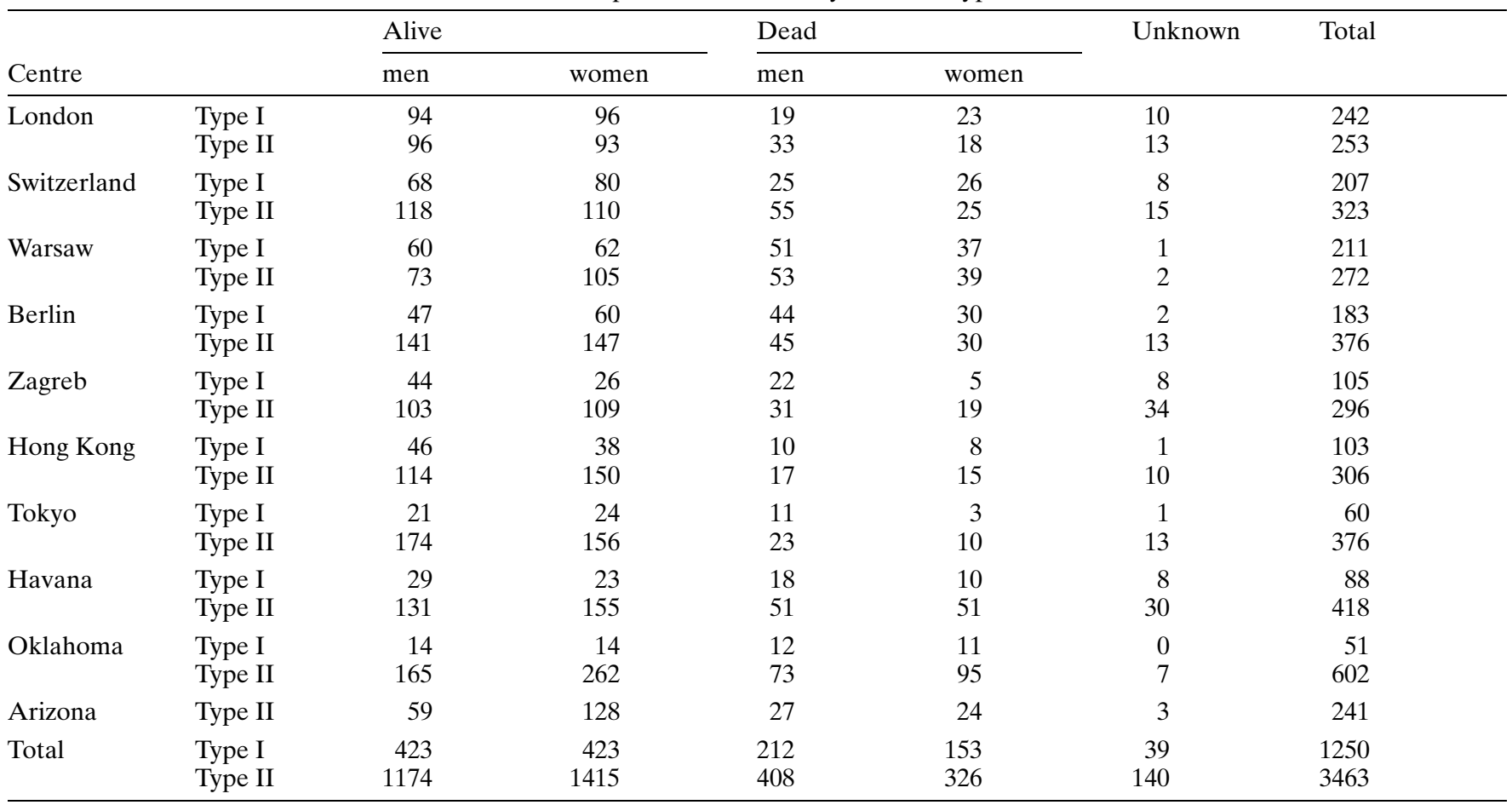

Table 3. Mean age at death of deceased patients for each centre by diabetes type and sex

\begin{tabular}{|c|c|c|c|c|c|c|c|c|}
\hline \multirow[b]{3}{*}{ Centre } & \multicolumn{4}{|c|}{ Type I (insulin-dependent) diabetes mellitus } & \multicolumn{4}{|c|}{ Type II (non-insulin-dependent) diabetes mellitus } \\
\hline & \multicolumn{2}{|l|}{ men } & \multicolumn{2}{|c|}{ women } & \multicolumn{2}{|l|}{ men } & \multicolumn{2}{|c|}{ women } \\
\hline & mean & SD & mean & $\mathrm{SD}$ & mean & SD & mean & SD \\
\hline Switzerland & 52.0 & 6.9 & 52.5 & 7.6 & 56.0 & 6.0 & 55.3 & 7.1 \\
\hline Warsaw & 52.4 & 6.9 & 53.7 & 6.4 & 57.3 & 5.5 & 57.2 & 4.5 \\
\hline Berlin & 52.0 & 7.8 & 52.0 & 6.5 & 56.7 & 5.5 & 56.7 & 5.8 \\
\hline Tokyo & 49.8 & 3.6 & 60.0 & 8.6 & 55.8 & 6.5 & 55.2 & 7.4 \\
\hline Havana & 50.8 & 6.3 & 50.8 & 4.2 & 53.8 & 6.4 & 54.1 & 6.1 \\
\hline Oklahoma & 53.0 & 5.0 & 56.6 & 7.2 & 55.1 & 6.2 & 54.8 & 6.4 \\
\hline Arizona & - & - & - & - & 53.5 & 6.4 & 54.3 & 6.4 \\
\hline Total & 51.9 & 6.5 & 53.4 & 6.5 & 55.1 & 6.2 & 55.2 & 6.1 \\
\hline
\end{tabular}

saw having a rate 3.2 times that in Zagreb. The mortality rates in men with Type I diabetes exceeded those for women in all centres except London. The ratios of the rates for men to those for women were close to or greater than two in Zagreb, Havana and Berlin.

Mortality rates among men and women with Type II diabetes were considerably lower in Tokyo than in the other nine centres. If the Tokyo results are excluded there was a lesser variation between centres among patients with Type II diabetes than with Type I diabetes, being twofold in men and 2.5-fold in women. The mortality rates among patients with Type II diabetes were higher for men than for women in all ten centres. The rates for men in London, Warsaw,
Zagreb and Arizona were approximately twice as high as those for the women.

Overall, the mortality rates for patients with Type I diabetes were higher than those for Type II diabetes with the exception of the men in London and the women in Havana.

Standardised Mortality Ratios (SMRs). The all-cause SMRs for the ten WHO Study cohorts are given in Table 6 . The SMRs were significantly greater than 100 among the patients with diabetes in all centres except Tokyo.

Among patients with Type I diabetes SMRs for men ranged from 188 in London to 682 in Berlin and 685 in Havana. Among women with Type I diabetes, 
Table 4. Underlying causes of death for each centre by diabetes type and sex

\begin{tabular}{|c|c|c|c|c|c|c|c|c|c|}
\hline \multirow[b]{2}{*}{ Centre } & \multirow[b]{2}{*}{ Cause } & \multicolumn{4}{|c|}{ Type I (insulin-dependent) diabetes mellitus } & \multicolumn{4}{|c|}{ Type II (non-insulin-dependent) diabetes mellitus } \\
\hline & & men & $(\%)$ & women & $(\%)$ & men & $(\%)$ & women & $(\%)$ \\
\hline London & $\begin{array}{l}\text { Cardiovascular } \\
\text { Cancer } \\
\text { Diabetes } \\
\text { Renal } \\
\text { Others }\end{array}$ & $\begin{array}{l}9 \\
7 \\
1 \\
2 \\
0\end{array}$ & $\begin{array}{r}(47) \\
(37) \\
(5) \\
(11) \\
(0)\end{array}$ & $\begin{array}{r}11 \\
7 \\
1 \\
2 \\
1\end{array}$ & $\begin{array}{r}(50) \\
(32) \\
(5) \\
(9) \\
(5)\end{array}$ & $\begin{array}{r}21 \\
5 \\
0 \\
3 \\
3\end{array}$ & $\begin{array}{r}(66) \\
(16) \\
(0) \\
(9) \\
(9)\end{array}$ & $\begin{array}{r}11 \\
5 \\
0 \\
1 \\
1\end{array}$ & $\begin{array}{r}(61) \\
(28) \\
(0) \\
(6) \\
(6)\end{array}$ \\
\hline Warsaw & $\begin{array}{l}\text { Cardiovascular } \\
\text { Cancer } \\
\text { Diabetes } \\
\text { Renal } \\
\text { Others }\end{array}$ & $\begin{array}{r}22 \\
5 \\
1 \\
9 \\
13\end{array}$ & $\begin{array}{r}(44) \\
(10) \\
(2) \\
(18) \\
(26)\end{array}$ & $\begin{array}{r}17 \\
4 \\
1 \\
10 \\
5\end{array}$ & $\begin{array}{r}(46) \\
(11) \\
(3) \\
(27) \\
(19)\end{array}$ & $\begin{array}{r}32 \\
8 \\
0 \\
3 \\
10\end{array}$ & $\begin{array}{r}(60) \\
(15) \\
(0) \\
(6) \\
(19)\end{array}$ & $\begin{array}{r}29 \\
5 \\
0 \\
2 \\
3\end{array}$ & $\begin{array}{r}(74) \\
(13) \\
(0) \\
(5) \\
(8)\end{array}$ \\
\hline Zagreb & $\begin{array}{l}\text { Cardiovascular } \\
\text { Cancer } \\
\text { Diabetes } \\
\text { Renal } \\
\text { Others }\end{array}$ & $\begin{array}{l}4 \\
3 \\
0 \\
1 \\
9\end{array}$ & $\begin{array}{r}(24) \\
(18) \\
(0) \\
(6) \\
(53)\end{array}$ & $\begin{array}{l}1 \\
1 \\
0 \\
3 \\
0\end{array}$ & $\begin{array}{r}(20) \\
(20) \\
(0) \\
(60) \\
(0)\end{array}$ & $\begin{array}{r}16 \\
2 \\
2 \\
0 \\
9\end{array}$ & $\begin{array}{r}(55) \\
(7) \\
(7) \\
(0) \\
(31)\end{array}$ & $\begin{array}{l}9 \\
4 \\
0 \\
1 \\
4\end{array}$ & $\begin{array}{r}(50) \\
(22) \\
(0) \\
(7) \\
(22)\end{array}$ \\
\hline Hong Kong & $\begin{array}{l}\text { Cardiovascular } \\
\text { Cancer } \\
\text { Diabetes } \\
\text { Renal } \\
\text { Others }\end{array}$ & $\begin{array}{l}4 \\
1 \\
0 \\
2 \\
3\end{array}$ & $\begin{array}{r}(40) \\
(10) \\
(0) \\
(20) \\
(30)\end{array}$ & $\begin{array}{l}3 \\
0 \\
0 \\
2 \\
3\end{array}$ & $\begin{array}{r}(38) \\
(0) \\
(0) \\
(25) \\
(38)\end{array}$ & $\begin{array}{l}8 \\
1 \\
0 \\
3 \\
5\end{array}$ & $\begin{array}{r}(47) \\
(6) \\
(0) \\
(18) \\
(29)\end{array}$ & $\begin{array}{l}7 \\
2 \\
0 \\
4 \\
2\end{array}$ & $\begin{array}{r}(47) \\
(13) \\
(0) \\
(27) \\
(13)\end{array}$ \\
\hline Oklahoma & $\begin{array}{l}\text { Cardiovascular } \\
\text { Cancer } \\
\text { Diabetes } \\
\text { Renal } \\
\text { Others }\end{array}$ & $\begin{array}{l}9 \\
0 \\
0 \\
1 \\
2\end{array}$ & $\begin{array}{r}(75) \\
(0) \\
(0) \\
(8) \\
(17)\end{array}$ & $\begin{array}{l}2 \\
0 \\
1 \\
4 \\
4\end{array}$ & $\begin{array}{r}(18) \\
(0) \\
(9) \\
(36) \\
(36)\end{array}$ & $\begin{array}{r}34 \\
8 \\
4 \\
5 \\
19\end{array}$ & $\begin{array}{r}(49) \\
(11) \\
(6) \\
(7) \\
(27)\end{array}$ & $\begin{array}{r}40 \\
6 \\
3 \\
16 \\
28\end{array}$ & $\begin{array}{r}(43) \\
(6) \\
(3) \\
(17) \\
(30)\end{array}$ \\
\hline Arizona & $\begin{array}{l}\text { Cardiovascular } \\
\text { Cancer } \\
\text { Diabetes } \\
\text { Renal } \\
\text { Others }\end{array}$ & $\begin{array}{l}- \\
- \\
- \\
-\end{array}$ & & $\begin{array}{l}- \\
- \\
- \\
-\end{array}$ & & $\begin{array}{r}11 \\
1 \\
0 \\
4 \\
6\end{array}$ & $\begin{array}{r}(50) \\
(5) \\
(0) \\
(18) \\
(27)\end{array}$ & $\begin{array}{l}4 \\
5 \\
1 \\
7 \\
6\end{array}$ & $\begin{array}{r}(17) \\
(22) \\
(4) \\
(30) \\
(26)\end{array}$ \\
\hline Total & $\begin{array}{l}\text { Cardiovascular } \\
\text { Cancer } \\
\text { Diabetes } \\
\text { Renal } \\
\text { Others }\end{array}$ & $\begin{array}{r}95 \\
19 \\
9 \\
31 \\
50\end{array}$ & $\begin{array}{r}(47) \\
(9) \\
(4) \\
(15) \\
(25)\end{array}$ & $\begin{array}{r}62 \\
20 \\
7 \\
35 \\
27\end{array}$ & $\begin{array}{r}(41) \\
(13) \\
(5) \\
(23) \\
(18)\end{array}$ & $\begin{array}{r}210 \\
55 \\
10 \\
31 \\
85\end{array}$ & $\begin{array}{r}(54) \\
(14) \\
(3) \\
(8) \\
(22)\end{array}$ & $\begin{array}{r}156 \\
44 \\
9 \\
45 \\
64\end{array}$ & $\begin{array}{r}(49) \\
(14) \\
(3) \\
(14) \\
(20)\end{array}$ \\
\hline
\end{tabular}

Cardiovascular deaths ICD Codes 390-459, 798.1; Cancer deaths ICD 140-209;

Diabetes deaths ICD 250 excluding 250.3 (nephropathy); Renal deaths ICD 580-589, 250.3; Other all other ICD codes 
A Type I diabetes

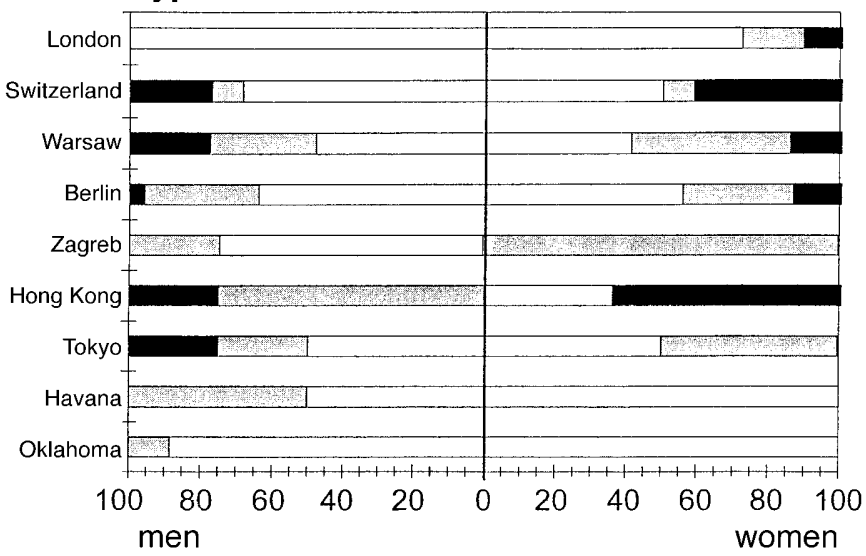

B Type II diabetes

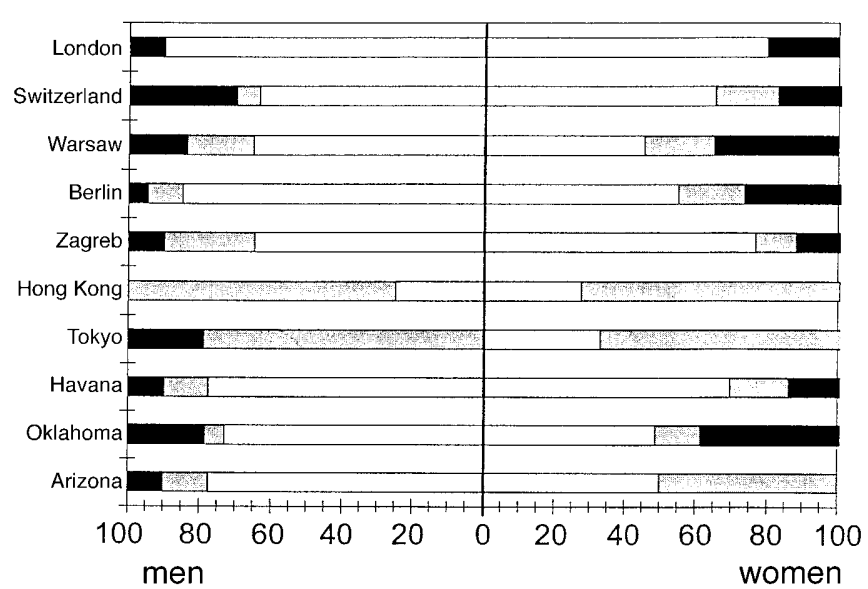

Fig.3A, B. Percentage of cardiovascular deaths assigned to Ischaemic Heart Disease (IHD), Cerebrovascular Accident (CVA) and other causes by centre, diabetes type and sex. $\square$, IHD; $\square$, CVA; $\square$, other (See text for relevant ICD-Codes)

SMRs were lowest in London (388) and Zagreb (346) and highest in Havana (790) and Switzerland (742). In the other centres the SMRs were all greater than 600 for women with Type I diabetes. The SMRs for women with Type I diabetes were greater than those for men except in Zagreb and Berlin where they were similar in the two sexes. Among patients with Type II diabetes SMRs were greater among women than men in eight out of the ten centres although differences were minimal in London and Switzerland. The SMR was slightly greater for men than for women in Arizona and Tokyo.

Standarised mortality ratios were greater among patients with Type I than those with Type II diabetes for both sexes except for the men in the London cohort.

\section{Discussion}

Routine mortality statistics do not provide reliable information on diabetes mortality because of the inaccuracies of death certifications [1]. The well known failure to mention diabetes or to classify it as the underlying cause of death probably leads to an underestimation of diabetes-related mortality. Cohort studies have been carried out but these have used differing method, differing (or absent) definitions of Type I and Type II diabetes and differing age and sex distributions. These differences make comparisons between these cohorts problematic. Moreover the known differences between background mortality in the general populations [11, 12] adds a further confounding factor in attempts to compare independent cohort studies. Some of the WHO MSVDD centres, such as Havana, Zagreb, Hong Kong and Berlin had little previous information available on diabetes mortality and our study provided a unique opportunity to compare mortality in these populations.

There are few international comparisons of diabetes mortality. The Diabetes Epidemiology Research International (DERI) Mortality Study [12] looked at mortality among patients with Type I diabetes from 1965 to 1985 . There was considerable international variation in all-cause mortality among subjects from Japan (6.81 per 1000 person-years), Finland (2.30) and Allegheny County, Pennsylvania, United States (1.31). The high mortality in Japanese patients with Type I diabetes contrasts with the low mortality rates in the patients with Type II diabetes from the Tokyo centre in the WHO MSVDD, the age groups studied were, however, different with the DERI patients having a maximum age of 40 years.

In this study the mortality rates for Type I diabetes were higher than those for Type II diabetes. This might be a function of the longer duration of diabetes in patients with Type I diabetes in the WHO Study but the adjustment for diabetes duration only caused marginal changes in the ratios with the average still being 1.5.

The all-cause SMRs in this study were between 300 and 800 in patients with Type I diabetes and between 140 and 400 in patients with Type II diabetes. A review showed a range of relative risk of between 200 and 800 in patients with Type I diabetes [13]. Another study [14] showed all-cause mortality rates in Type II diabetes to be approximately twice as high as those of non-diabetic subjects. All the centres except Tokyo had a SMR higher than 100 for both men and women; this indicates a global impact of diabetes on mortality.

In Type II diabetes the absolute rates for mortality in women were lower than for men in most centres but the SMRs were greater. This loss of survival advantage has been noted in other studies for women with diabetes $[15,16]$ and could be due to a relative 
Table 5. Age-adjusted all-cause mortality rates per 1000 person years (standard errors) for each centre by diabetes type and sex and sex ratios

\begin{tabular}{|c|c|c|c|c|c|c|c|c|c|c|}
\hline \multirow[b]{2}{*}{ Centre } & \multicolumn{5}{|c|}{ Type I (insulin-dependent) diabetes mellitus } & \multicolumn{5}{|c|}{ Type II (non-insulin-dependent) diabetes mellitus } \\
\hline & men & & wome & & $\begin{array}{l}\text { men/ } \\
\text { women }\end{array}$ & men & & wome & & $\begin{array}{l}\text { men/ } \\
\text { women }\end{array}$ \\
\hline Switzerland & 25.5 & $(5.8)$ & 24.1 & $(5.2)$ & 1.06 & 21.6 & (3.1) & 15.8 & $(4.6)$ & 1.37 \\
\hline Warsaw & 39.7 & $(10.5)$ & 39.2 & (9.1) & 1.01 & 29.3 & (4.6) & 16.5 & $(2.7)$ & 1.78 \\
\hline Berlin & 54.2 & $(11.6)$ & 29.8 & $(6.0)$ & 1.82 & 15.4 & (2.4) & 11.0 & $(2.3)$ & 1.40 \\
\hline Zagreb & 37.0 & $(7.5)$ & 12.4 & (5.6) & 2.98 & 18.3 & (3.5) & 8.9 & $(2.2)$ & 2.06 \\
\hline Havana & 33.8 & $(14.0)$ & 13.5 & (9.2) & 2.50 & 26.1 & (5.5) & 20.1 & $(3.0)$ & 1.30 \\
\hline Oklahoma & - & & - & & - & 23.7 & (2.9) & 22.5 & $(3.0)$ & 1.05 \\
\hline Arizona & - & & - & & - & 31.5 & (6.5) & 16.7 & $(5.4)$ & 1.89 \\
\hline
\end{tabular}

Table 6. All-cause Standardised Mortality Ratio (SMR) with $95 \%$ confidence intervals for each centre by diabetes type and sex

\begin{tabular}{|c|c|c|c|c|c|c|c|c|}
\hline \multirow[b]{2}{*}{ Centre } & \multicolumn{4}{|c|}{ Type I (insulin-dependent) diabetes mellitus } & \multicolumn{4}{|c|}{ Type II (non-insulin-dependent) diabetes mellitus } \\
\hline & men & & won & & men & & won & \\
\hline London & 188 & $(113-294)$ & 338 & $(214-507)$ & 225 & $(154-318)$ & 230 & $(136-363)$ \\
\hline Warsaw & 427 & $(317-562)$ & 700 & $(493-964)$ & 262 & $(199-345)$ & 372 & $(265-509)$ \\
\hline Berlin & 682 & (495-915) & 655 & $(435-946)$ & 198 & $(145-265)$ & 229 & $(155-327)$ \\
\hline Zagreb & 346 & $(214-528)$ & 336 & $(109-784)$ & 167 & $(113-239)$ & 212 & $(126-335)$ \\
\hline Hong Kong & 344 & $(165-632)$ & 637 & $(275-1255)$ & 223 & $(128-363)$ & 333 & $(186-549)$ \\
\hline Oklahoma & - & & - & & 267 & $(212-335)$ & 433 & $(353-532)$ \\
\hline Arizona & - & & - & & 314 & (207-457) & 228 & (141-348) \\
\hline
\end{tabular}

loss of protection from cardiovascular deaths among women with diabetes $[8,17]$. This study also found that women with Type I diabetes tended to have a higher excess mortality than men with Type I diabetes.

Cardiovascular causes were responsible for a higher percentage of deaths in patients with Type II diabetes than those with Type I diabetes in both sexes but the rates were considerable even in Type I diabetes (men $47 \%$, women $41 \%$ ). It is difficult to compare mortality studies directly because of differences in patient selection criteria, particularly age and diabetes duration, but these results are in broad accord with other reports including older, long duration patients with Type I diabetes $[18,19]$. The WHO MSVDD follow-up has emphasised the importance of cardiovascular disease in Type I as well as in Type II diabetes and has shown that there are considerable variations among different populations with diabetes.

The proportion of renal deaths in this study in patients with Type I diabetes (men $8 \%$, women $16 \%$ ) is comparable to that found in a large follow-up study in Denmark [20] but lower than that found in studies which looked at younger patients $[12,21]$. In patients with Type II diabetes the percentage of deaths from renal causes is $8 \%$ for men and $14 \%$ for women.
This is higher than in some older studies [22] but the difficulty in characterising the exact nature of the 'renal' death in the WHO cohort makes comparison difficult. The percentage of renal deaths in the Hong Kong men and in the Pima Indians of both sexes is about double the average but both had a lower proportion of cardiovascular deaths. High rates of renal disease among the Pima Indians have been noted [23].

The WHO mortality follow-up provides a large amount of information on the causes of death among patients with diabetes in the participating centres and shows that although there is broad similarity in most areas of the results, there are also major differences between the centres in certain respects. The use of a common methodology increases the likelihood that the differences are real and emphasises the importance of using local data for health planning.

\section{References}

1. Fuller JH, Elford J, Goldblatt P, Adelstein AM (1983) Diabetes mortality: New light on an underestimated public health problem. Diabetologia 24: 336-341 
2. World Health Organization Study Group on Diabetes Mellitus (1988) Technical report series No 727, WHO, Geneva

3. Krolewski AS, Warram JH, Christlieb AR (1985) Onset, course and prognosis of diabetes mellitus. In: Marble A, Krall LP, Christlieb AR, Soeldner JS (eds) Joslin's Diabetes Mellitus 12th ed, Lea \& Febiger, Philadelphia, pp 251-777

4. Pell S, D'Alonzo A (1970) Factors associated with longterm survival in diabetics. JAMA 214: 1833-1840

5. Kleinman JC, Donahue RP, Harris MI, Finucane FF, Madans JH, Brock DB (1988) Mortality among diabetics in a national sample. Am J Epidemiol. 128: 389-401

6. Borch-Johnsen K, Kreiner S (1987) Proteinuria: value as a predictor of cardiovascular mortality in diabetes mellitus. BMJ 294: 1651-1654

7. Reunanen A (1983) Mortality in type 2 diabetes. Ann Clin Res 15 [Suppl 37]: 26-28

8. Barrett-Connor E, Wingard D (1983) Sex differential in ischaemic heart disease mortality in diabetes: A prospective population based study. Am J Epidemiol 118: 489-496

9. Stamler J, Vaccaro O, Neaton JD, Wentworth D (1993) Diabetes, other risk factors and 12 year cardiovascular mortality for men screened in the Multiple Risk Factor Intervention Trial. Diabetes Care 16: 434-444

10. Diabetes Drafting Group (1985) Prevalence of small vessel and large vessel disease in diabetic patients from 14 centres. The WHO Multinational Study of Vascular Disease in Diabetes. Diabetologia 28: 615-640

11. Diabetes Epidemiology Research International Mortality Study Group (1991) Major cross-cultural differences in risk of dying for people with Type I diabetes. Diabetes Care 14: 49-54

12. Diabetes Epidemiology Research International Mortality Study Group (1991) International evaluation of cause specific mortality and Type I diabetes. Diabetes Care 14: 49-54

13. Nystrom L, Ostman J, Wall S, Wibell L (1992) Mortality of all incident cases of diabetes mellitus diagnosed in Sweden in 1983-1987 at age 15-34 years. Diabet Med 9: 422-427

14. Panzram G (1987) Mortality and survival in Type II (noninsulin dependent) diabetes mellitus. Diabetologia 30: 123-131

15. Panzram G, Zabel-Langhenning R (1981) Prognosis of diabetes mellitus in a geographically defined population. Diabetologia 20: $587-591$
16. O'Sullivan JB, Mahan CM (1982) Mortality related to diabetes and blood glucose levels in a community study. Am J Epidemiol 116: 678-684

17. Orchard TJ (1996) The impact of gender and general risk factors on the occurrence of atherosclerosic vascular disease in non-insulin dependent diabetes mellitus. Ann Med 28: 323-333

18. Connell FA, Louden JM (1983) Diabetes mortality in persons under 45 years of age. Am J Public Health 73: 1174-1177

19. Borch-Johnsen K, Norgaard K, Hommel E (1992): Is diabetic nephropathy an inherited complication? Kidney Int 41: 719-722

20. Borch-Johnsen K (1993) Epidemiology of microangiopathy in type 1 diabetes mellitus. A review. Diabetes Metab 19: $133-137$

21. Deckert T, Poulsen JE, Larsen M (1978) Prognosis of diabetics with diabetes onset before the age of thirty one: 1 survival, causes of death and complications. Diabetologia 14: $363-370$

22. Palumbo PJ, Elveback LR, Chu CP, Connolly DC, Kurland LT (1976) Diabetes mellitus: incidence, prevalence, survivorship, and causes of death in Rochester, Minnesota, 1945-1970. Diabetes 25: 566-573

23. Sievers ML, Nelson RG, Knowler WC, Bennett PH (1992) Impact of non-insulin dependent diabetes mellitus on mortality and causes of death in Pima Indians. Diabetes Care 15: $1541-1549$

24. Head J, Fuller JH (1990) International variations in mortality among diabetic patients: the WHO Multinational Study of Vascular Disease in Diabetes. Diabetologia 33: 477-481

25. Wang SL, Head J, Stevens L, Fuller JH (1996) Excess mortality and its relation to hypertension and proteinuria in diabetic patients: the WHO Multinational Study of Vascular Disease in Diabetes. Diabetes Care 19: 305-312

26. Lee ET, Lu M, Bennett PH, Fuller JH, Keen H, and the WHO Multinational Study Group (2001) Follow up of the WHO Multinational Study of Vascular Disease in Diabetes; general description and morbidity. Diabetologia 44 [Supp 2]: S3-S13 